\title{
CAMBIO SOCIAL Y MODERNIZACIÓN EN UNA INSTITUCIÓN HOSPITALARIA RELIGIOSA
}

\author{
Adolfo Perinat \\ (Universidad Autónoma de Barcelona)
}

Se estudia un proceso de modernización en una institución religiosa hospitalaria, analizando los condicionamientos estructurales, propios de la comunidad religiosa y de su actividad caritativo-asistencial, que enmarcan el proceso de cambio y modernización. Este último comenzó hace siete años, y en la actualidad prosigue su desarrollo. Se analiza someramente la estrategia del cambio en la parte que afecta al cuerpo médico de los hospitales y un poco más a fondo la parte referente a la comunidad religiosa. Se establece un balance provisional y se anticipan consecuencias a más largo plazo centradas sobre todo en la mutación que sufre el modo de presencia de los religiosos en un hospital-empresa. 



\section{Introducción}

El número de hospitales, clínicas y centros sanitarios a cargo de religiosos de ambos sexos es aún hoy en España notable. Al igual que otros muchos campos de actividad de la Iglesia, éste, el sanitario-asistencial, sufre también sus conmociones. Muchos grupos religiosos que trabajan aquí se preguntan -entre el estupor y la angustia - acerca de los modos y las razones de su presencia en el ámbito de la asistencia sanitaria. Buena parte de ellos están tratando, más o menos airosamente, de adaptarse a otros estilos de hospitalidad que los que aprendieron y han vivido hasta ahora. En algún caso aislado, grupos más lúcidos han creído conveniente someterse a un diagnóstico sociológico que pudiera ayudarles a salir del impasse. Del verano de 1973 al de 1974 un pequeño equipo de sociólogos tuvo la oportunidad de estudiar de cerca una serie de hospitales dirigidos por una congregación religiosa de varones. ${ }^{1}$ Fruto de ese contacto con esa realidad social, el centro hospitalario, son estas reflexiones en torno a un proceso de modernización cuyo escenario es precisamente el hospital.

Un hospital es una organización muy compleja. Nacido en un contexto religioso, de asistencia caritativa, ha ido poco a poco «secularizándose». Más temprano en los países sajones que en los mediterráneos, el hospital fue considerado como institución a cargo de la gestión pública. ${ }^{2}$ Concretamente en España la «medicina socializada» data de la década de los sesenta, en que la seguridad social ha tomado definitivamente las riendas de la sanidad. Aún quedan sin embargo centros hospitalarios

1. El estudio se ha realizado en el marco del Instituto de Sociología y Psicología Aplicada ISPA de Batcelona, y ha sido objeto de un extenso informe titulado Análisis socio-religioso de una institución bospitalaria (Barcelona: ISPA, Estudio n. 103 , mimeografiado, 1974). En él tomó parte muy especial el doctor Rogelio Duocastella, director de ISPA, con cuyo concurso fue elaborado el informe.

2. Rodney M. Coe, Sociología de la medicina (Madrid: Alianza, 1970), p. 275. 
privados. Muchos de ellos son clínicas de selecta clientela, otros están reservados a un cupo de asociados o asegurados, otros tienen un carácter asistencial más abierto a clases populares. Aquí figuran muchas instituciones religiosas al frente, incluso como propietarias, de los mismos; éste es nuestro caso.

Sin perjuicio a que desarrollemos luego más a fondo ciertos temas, es conveniente ya desde aquí enmarcar la problemática de estos centros. Es un tópico en la literatura especializada sobre hospitales hablar de las «dos líneas de autoridad»: administración y cuerpo médico. ${ }^{3}$ Sin embargo, en un hospital tradicional dirigido por religiosos la «administración» no recubre exactamente lo que esa palabra dejaría entender a primera vista. La «administración» es la comunidad religiosa que no tanto administra (al menos si por esto entendemos un sentido actual de la gestión de que adolecen tantos hospitales) cuanto que está presente al lado del cuerpo médico y personal sanitario, actuando profesionalmente con los enfermos. La relación, pues, de la comunidad religiosa al hospital (en cuanto que son propietarios y administradores, en cuanto que viven y trabajan allí dentro) es particularmente intensa. En cierto modo los religiosos definen el "estilo» de asistencia, aunque los médicos no se vean interferidos por ellos en los dominios estrictamente de su competencia. En cuanto al personal sanitario su posición es muy secundaria y en los hospitales más tradicionales es más precaria que en empresas de otra índole.

Nosotros nos centraremos principalmente en nuestro análisis en la comunidad religiosa que está al frente de los hospitales. En cierto modo el estudio guía sugiere también esta línea. Esto no quiere decir que minimicemos la presencia de los otros grupos en el hospital. Los médicos, particularmente, pesan demasiado como para que no los tengamos en consideración. Se trata solamente de justificar una opción tanto más cuanto que el sentido implícito de todo este proceso de modernización que estudiamos es, en cierto modo, un proceso de «secularización» de la presencia de los religiosos en el hospital. Todo aboca a reinterpretar esta presencia más como los animadores de una asistencia sanitaria modelo (racional, humana, desinteresada) que como los sustentadores de una actividad caritativo-religiosa.

3. Harvey L. Smith, «Un double système d'autorité: Le dilemme de l'hôpital», pp. 252-262, en C. Herzlich (ed.), Médicine, maladie et société (París: Mouton, 1970). 
Los problemas implicados en un proceso de cambio, en el sentido de modernización, son muy vastos y además diferentes en las diversas unidades sociales. No son los mismos en una organización industrial que en una colectividad humana dedicada a un modo de producción; están las peculiaridades de sus modos de producción específicos y de las relaciones que de ellos se derivan, así como las diferencias de medio - urbano o rural- en que las colectividades se insertan.

Un centro hospitalario es una unidad social sui generis; también lo es, por otros conceptos, una comunidad religiosa, y eso con independencia de que se dedique a la asistencia sanitaria, a la dolencia o a la vida contemplativa. Es con todo evidente que en la articulación del modo de vida de una comunidad incide su tipo de actividad propio.

Nuestro punto de partida para el estudio que emprendemos es la comunidad religiosa: su estructura de vida y el modo como se inserta en ella la actividad de sus miembros, así como la imagen o representación colectiva que ellos se dan acerca de esta actividad.

El conjunto de hospitales que hemos tenido ocasión de estudiar son propiedad (excepto uno) de la institución religiosa. Al frente de cada uno de ellos ha estado desde siempre una comunidad de religiosos. Ellos concretizan alli la presencia de la institución y entiende así inculcar sus valores institucionales traduciéndolos en un estilo de asistencia al enfermo que se proclama original y heredero de una tradición propia del grupo.

Una comunidad religiosa está ya muy lejos del convento tradicional pero no tanto como para que no se le pueda aplicar con bastante exactitud el modelo estructural de Goffman de las «instituciones totales».4 Para este autor, toda institución total (un grupo religioso particularmente) se apoya sobre cuatro pilares fundamentales. ${ }^{5}$ El primero es la ruptura con el medio ambiente social (l'environnement social) que se materializaba hasta ahora en una existencia más o menos claustrada, aparte de la sociedad. El segundo es el poder absorbente y acaparador del reglamento de vida diario; el religioso se somete a él en virtud de su promesa de obediencia. El tercero es la disociación que sufre el trabajo de un religioso de su correspondiente valoración económico-salarial, lo cual es consecuencia de que la institución le provee de morada y subviene a

4. Ervin Goffman, Asiles (Patís: Minuit, 1968), p. 447. Prólogo de Robert Castel.

5. Este tema queda desarrollado en mi tesis doctoral: «Incidences d'une idéologie religieuse dans une organisation éducative» (París: Ecole Practique des Hautes Etudes-Sorbonne, 1975). 
todas sus necesidades. Finalmente la vida religiosa, como toda institución total, genera un foco de separación, un biatus, entre las instancias de poder y de decisión y las de ejecución (los superiores/los inferiores).

Es importante captar las consecuencias más inmediatas de este modo de estructura organizativa, pues todo el proceso de cambio y modernización está fuertemente condicionado a las mismas. Todo marco de vida marginal al resto de la sociedad tiende a decantar una subcultura específica la cual - como escribe $R$. Castel de las instituciones totales«posee su sistema de valores, sus pautas de comportamiento específicas, un código de sanciones, unos símbolos de prestigio, unas vías de promoción». Ello se explicita en un discurso que el grupo religioso elabora para su propio consumo y que, en tanto es un conjunto de opiniones fundado en un sistema de valores, lo calificaremos de discurso ideológico o ideología del grupo religioso.' Ésta es un elemento fundamental del sistema simbólico que un grupo social peculiar posee como clave de acceso a «la realidad». Es importante hacer notar cómo, dentro de ese sistema simbólico, la actuación del religioso no es interpretada como actividad profesional sino como acción religiosa, y recibe, en consonancia, los calificativos de apostolado y testimonio.

Otra consecuencia importante de la organización de la vida de los miembros de las instituciones totales se refiere a la ranera como el trabajo se inscribe en su existencia y, a la larga, en su propia «visión del mundo». Disociado de toda estimación salarial correlativa, las relaciones de producción (trabajo-salario) que arbitran tantos comportamientos en nuestra sociedad son inexistentes dentro de la vida religiosa tradicional. El hecho de que el trabajo personal de los religiosos no esté orientado por el deseo de lucro tiene consecuencias muy concretas en la forma como se racionaliza este trabajo, en su intensidad y dedicación, en su rendimiento y hasta en la imagen que los religiosos tienen de su actividad frente a la actividad idéntica que los seglares realizan a su lado

6. Robert Castel, «Presentation», en E. Goffman, Asiles, op. cit.

7. Seguimos en esto la definición que da Adam Schaff de ideología: «Un sistema de valores compartidos que determinan las actitudes y los comportamientos de un grupo con respecto a ciertos objetivos que se persiguen en relación con el des. arrollo de la sociedad, del grupo social o del individuo»; en «La définition fonctiornelle de l'idéologie et le problème de la fin du siècle des idéologies», L'bome et la société, vol. 1, n. ${ }^{\circ} 4$ (1967): 49-59, p. 50.

8. El sistema simbólico se puede definir como la lectura significativa que un grupo hace de su existencia real, de su situación económica, de su posición social. de sus actividades. Véase, por ejemplo, Lucien Legrand y Pierre Meyers, Analyse socio-linguistique comparative de deux documents pontificaux (Lovaina: Université Catholique, Fac. Sc. Economiques et Sociales, mimeografiado, 1972), p. 264. 
(por ejemplo en un colegio, en un hospital). También de aquí se seguiría la resistencia que los religiosos ofrecen a una racionalización de la gestión económica de sus «empresas».

Por último, haremos mención, en este rápido recorrido, de las consecuencias del gap existente en un grupo religioso, entre superiores e inferiores. La concentración del poder y de la decisión en aquéllos, junto con el acatamiento a las normas reforzado por la obediencia religiosa, no dejan al miembro de la comunidad casi otro modo de participación en la actividad del grupo que a nivel de «ejecutivo», o sea, en la forma de tareas precisas y programadas como pueden serlo las del hospital. Éstas tienden a caracterizarse por un alto grado de performance y una fuerte intensidad de dedicación cotidiana. Pero, en contrapartida, se da un desinterés general por la marcha de la organización y de su problemática global a otros niveles que no se relacionan inmediatamente con esa tarea. La falta de perspectiva y desconocimiento del contexto social que tanto condiciona la institución suelen ser, en definitiva, flagrantes entre los religiosos.

Dentro de este dominio no es tampoco sorprendente el que apenas ninguna iniciativa o corriente innovadora provenga de «la base»; antes bien, éstas, si se dan, provienen desde arriba (via jerárquica) o de presiones exteriores, e incluso disposiciones legislativas. Delegar la decisión en una instancia especializada supone, la mayor parte de las veces, relegar también la reflexión. La dicotomía de funciones que estamos comentando puede ser muy cómoda para eliminar conflictos pero es disfuncional para la adaptación de la organización.

No es éste el lugar de efectuar la crítica de este modo de organización de la acción y, menos aún, de emitir juicios de valor acerca de ella. Sólo hemos pretendido clarificar un modo estructural de organizar la actividad propia de los religiosos, para comprender más de cerca los condicionantes de un proceso de cambio.

Tratemos ahora de situar este marco estructurador en la concreción de un hospital tradicional. La comunidad religiosa es omnipresente; quien le da forma y define su estilo. La comunidad vive en el hospital, aquélla es su casa (tiene un ala o un piso reservados que son «clausura»). Es decir, no hay ruptura espacial entre el lugar de vida y el lugar de trabajo para los religiosos. Son ellos quienes acogen en su casa a los enfermos y también a los médicos y personal sanitario cuyo concurso les es preciso. En definitiva, en su sistema de representaciones culturales, el lugar de trabajo no posee una especificidad intrínseca a lo que allí se hace (curar), sino que se integra como un elemento más, apenas diferenciado, de un «medio ambiente de vida». El hospital es el «otro» aspecto del convento, un anexo del mismo. De ahí las interferencias constantes que se dan entre 
lo religioso y lo profesional: horarios del hospital supeditados a la comunidad, contabilidad indiferenciada y confusa, relaciones laborales y salariales regidas por normas de una ingenuidad sorprendente.

En contrapartida, la actividad de asistencia es todo un derroche de energías y abnegación. Años atrás (como señala un religioso maduro en una entrevista) eran los religiosos quienes soportaban prácticamente toda la carga del hospital: ellos hacían las camas, servían la comida, administraban medicamentos, velaban por la noche y todo ello sin detrimento de sus obligaciones de presencia en la comunidad. El hospital era, por otra parte, un organismo indiferenciado con pocas funciones especializadas y donde los religiosos podían ocupar sin compromiso cualquier puesto (de hecho los cambiaban con frecuencia). Su preparación profesional era muy reducida y hasta se les aconsejaba renunciar a los estudios en aras de una dedicación mayor. Sin embargo, en contacto con los médicos y el personal más especializado, llegaban a adquirir cierta técnica y destreza. Pero en conjunto mantenían con los enfermos una relación terapéutica «mágica» en el sentido de que era sobre todo un gesto religioso el que realizaban a través de su presencia día y noche en el hospital.

Sería una ligereza subestimar este estilo de asistencia curativa (de por sí insuficiente, claro está). Precisamente el gran problema que se plantea al hospital religioso es injertar la nueva racionalidad en su estilo propio de relación terapéutica, esto es, hacer pervivir el gesto y una actitud en medio de la balumba de refinamientos que escoltan el proceso curativo. «La medicina primitiva -escribe Ackerknecht- era esencialmente mágicoreligiosa, mientras que la nuestra es fundamentalmente racional y científica, bien que conserva elementos mágicos y míticos que sería erróneo menospreciar.»"

El cuerpo médico albergaba, con respecto al hospital, sentimientos ambivalentes. Por una parte podía encontrarse muy vinculado a él y a los religiosos pero por otra no podía dedicarse a full-time (y esto era la mayoría de los casos) ya que la remuneración económica que obtenía era escasa. De un lado, admiración hacia los religiosos que aseguraban servicios y suplencias sin regateos y, de otro, un si-es no-es de conmiseración ante su escaso nivel de preparación y la posición «fuera de juego» en que se iban confinando. La situación aparece descrita globalmente en el siguiente párrafo escrito a propósito de los hospitales del siglo pasado: «El hospital no es el lugar privilegiado de trabajo y de formación del médico profesional como lo ha de ser más tarde. El médico conserva una

9. Erwin H. Ackerknecht, «Natural diseases and rational treatment in primitive medecine», Bulletin of the History of Medecine, vol. 19 (1964): 468. 
amplia autonomía frente al hospital. Como la mayoría de los cuidados (cuya eficacia era limitada por el estado del saber y de la técnica) estaban asegurados por las religiosas, el médico no bacía más que pasar. Un cuerpo médico estaba vinculado en permanencia al hospital pero sus efectivos eran escasos; muchos se dedicaban primordialmente a su clientela privada ante la cual hacían valer sus titulos hospitalarios. $\rangle^{10}$

Desde el punto de vista organizativo todo este microcosmos funcionaba según un esquema de organización natural: ${ }^{\text {11 }}$ relaciones inmediatas con visos de paternalismo y proteccionismo, solución autoritaria de los conflictos, objetivos nunca explicitados en programas y nunca sometidos a control. Las estructuras organizativas se mantenían espontáneamente y los cambios eran lentos e insignificantes. En todo caso, suponían respuestas adaptativas, teñidas de reflejos defensivos, a ciertas perturbaciones que amenazaban el equilibrio del sistema. Las nuevas decisiones que a veces se tomaban iban casi siempre encaminadas a evitar que se rompiese este equilibrio (el orden, la sumisión a la jerarquía). Si algún plan fracasaba, no eran los errores ni la impericia o ignorancia de los dirigentes sino dificultades de fuera. El que los miembros de la organización desconociesen casi todo lo que concernía al dominio económico, de toma de decisiones, política de personal, nadie lo consideraba como inconveniente sino, al contrario, muy funcional.

La enumeración acumulativa de todas estas características pudiera interpretarse como un juicio de valor negativo para el hospital religioso antiguo. Nada más lejos de nuestra intención. Todo esto era un marco, más que organizativo cultural, de una época. Más aún, la presencia y dedicación total de los religiosos (que cubrían fundamentalmente el objetivo asistencial) constituyen una forma de racionalidad como lo es, a su manera, el gesto curativo que impetra el milagro. La racionalidad actual es, en todo caso, diferente. Hoy día exigimos que pase por un refinado análisis psicosocial y económico de la unidad hospitalaria y que luego establezca vínculos funcionales entre el resultado de estos análisis, por una parte, y las decisiones operativas, por otra. La diferencia de racionalidades radica pues en el requisito previo del análisis y en la funcionalidad de los medios: antiguamente eran casi exclusivamente gestos (cuidados caritativos, abnegación y presencia, oración); hoy tienden a ser predominantemente productos $\mathrm{y}$ habilidades (fármacos, instrumentos de diagnóstico, técnicas quirúrgicas).

10. François Steudler, «Hôpital, profession médicale et politique hospitalière* Revue Française de Sociologie, vol. 14 (1973): 13-40.

11. Alvin Gouldner, «Organizational Analysis», pp. 404-410, en R. K. Merton, L. Broom y L. Cottrell (eds.), Sociology Today (Nueva York: Basic Books, 1959). 
La repercusión de esta mutación en el ámbito de la organización hospitalaria religiosa es lenta y desigual. No todos sus estamentos (médicos, religiosos, personal auxiliar sanitario) se sienten igualmente concernidos ni por los mismos motivos implicados en la corriente de modernización. Primero, porque no todos llegan al mismo nivel de profundidad en su análisis de los condicionamientos en el ejercicio de la sanidad y de sus consecuencias. Segundo, porque la puesta en marcha de un proceso de modernización atenta, a veces violentamente, a modos de comportarse muy bien cristalizados y suponen un trastorno ecológico que postula una readaptación consiguiente.

En lo que respecta a la comunidad religiosa que dirige el hospital podemos imaginar la «resistencia estructural» (por el hecho de su configuración como institución total) que ofrece. Muy particularmente, dentro de ella la dificultad de innovación nace de un elemento ideológico propio de la subcultura. En efecto, como apunta R. Bastide, hay una especie de contradicción in terminis cuando se habla de mutación en lo religioso, ya que lo religioso se inscribe en la línea de perpetuación de souvenirs que los seres humanos, los grupos, las instituciones tratan de reconstruir a lo largo de una vida cambiante. ${ }^{12}$ Lo cual no obsta para que los fundadores de congregaciones religiosas fuesen innovadores audaces creando nuevas formas de vida y de actividad; a sus seguidores se les exigió solamente reproducir el modelo. En nombre de la fidelidad al fundador y de la pervivencia de su gesto (interpretado por la memoria colectiva del grupo como religioso) se ha ahogado la capacidad creativa y de innovación de muchos grupos religiosos. Más aún, se ha abundado en cantar las propias excelencias de la Orden o de la Congregación alimentando la satisfacción de pertenecer a un grupo que, en conjunto, «todo lo hacía bien». En tales condiciones, ¿qué estímulo presenta la innovación para un religioso? $\mathrm{Si}$, por una parte, su vida es la reproducción de un souvenir $\mathrm{y}$, por otra, el juicio de sus actividades hecho por el grupo para consumo del grupo les ha dado invariablemente un balance positivo, ¿qué tiene de extraño que no se desencadene ese comportamiento de búsqueda o de exploración que nace de la insatisfacción de los resultados de ciertos programas de acción? Afortunadamente, después del Concilio Vaticano II la situación ha cambiado y se ha generado una toma de conciencia más realista por parte de los religiosos.

Por último, un proceso de cambio y modernización genera una gama de conflictos. Los grupos religiosos tienden a contemplar el conflicto desde

12. Roger Bastide, «Sociologie des mutations religieuses» pp. 157-162, en $G$. Balandier (ed.), Sociologie des mutations (París: Anthropos, 1970). 
un ángulo moral, o sea, lo envuelven con una connotación negativa. El conflicto atenta a la paz y a la armonía; es un producto de desecho en la relación fraternal; la discordia, la confrontación es el pecado. Sin embargo, los conflictos están presentes en todo proceso de modernización como parte integrante del mismo. Juegan un papel análogo al de los catalizadores de una reacción química: a veces la desencadenan, otras la regulan. De los grupos religiosos se puede decir lo mismo que de aquellos otros «conservadores» que «al dar la primacía a estos valores de integración y de armonfa olvidan que el descontento, las divisiones y los conflictos son el precio que una sociedad abierta debe pagar por el progresom..$^{13}$

He aquí pues, esquemáticamente, unos presupuestos para comprender la dinámica del cambio en una comunidad religiosa. Más que dinámica del cambio habría que hablar de estática de lo permanente (y valga la redundancia). Con respecto al grupo religioso, una subcultura marginal, tiene poco valor explicativo hablar del «peso de la tradición». No basta constatar cómo a través de la historia una estructura se reproduce: hay que explicar por qué. Es lo que hemos intentado bosquejar. Sólo en este contexto de perpetuación religiosa de un gesto original y carismático puede entenderse la reticencia ante lo nuevo y la falta de adaptación de que adolecen los religiosos. Sólo a partir de aquí puede captarse la conmoción con que irrumpe en su existencia una corriente modernizante.

\section{Análisis del proceso de modernización}

Comenzamos por hacer un poco de historia de los hechos, pues el caso que estamos tratando es real. Año 1967; el aggiornamento propugnado por el Concilio Vaticano II encuentra una resonancia inusitada dentro de muchos sectores de acción de la Iglesia que necesitaban una legitimación de sus proyectos de adaptación a la sociedad. En el dominio hospitalario-asistencial circula por todos los países una corriente de modernización acelerada. En España se promulga en 1962 la Ley de Hospitales que pretende «modernizar la estructura hospitalaria española, básicamente benéfica, transformándola en una organización asistencia dinámica e impregnando Ia gestión hospitalaria de un sentido empresarial». En 1966 se elabora un proyecto de Reglamento de Hospitales que alcanza amplia difusión y es objeto de apasionados debates en los medios sanitarios. Dentro del

13. Michael Crozier, Le phénomène bureatucratique (Paris: Le Seuil, 1963), $413 \mathrm{pp}$. 
ámbito católico la Confederación Internacional de Instituciones Hospitalarias trata asimismo de sensibilizar a sus miembros adherentes a la nueva problemática de la asistencia. Los contactos de ésta con los otros organismos internacionales (OMS, UNICEF, Federación Internacional de Hospitales) amplian considerablemente la perspectiva de los centros hospitalarios confesionales, que hasta entonces estaban prácticamente acantonados en su pequeño mundo. Al final de la década el hospital es lugar de confrontación de las técnicas más en punta con el savoir faire curativo, de una racionalización económica urgente con un sentido humanitario que entronca con la tradición benéfico-asistencial.

En esta coyuntura, la congregación religiosa objeto de nuestro estudio pone en marcha un proceso de reorganización dentro de sus propios establecimientos. Cuando decimos que un grupo «toma conciencia de» o «se decide a» estamos, evidentemente, hablando por analogía. Asimilamos un colectivo (el grupo) a la persona humana y en realidad estamos aludiendo a procesos sumamente complejos y escalonados a lo largo de períodos de tiempo. La dinámica de grupos nos permite captar, hasta cierto punto, los mecanismos de decisión del grupo y, en particular, los fenómenos de liderazgo, de persuasión, de presión que, dentro del mismo, abocan a un viraje de su línea de acción. No podemos analizar aquí estos aspectos que no tuvimos ocasión de seguir de cerca pero que conocemos por referencias. Baste decir que en el seno de la provincia religiosa se manifiesta un núcleo de religiosos, de un nivel de conocimientos más destacado y situados en puestos directivos, que provocan el movimiento de reforma.

A fines de 1967, el Superior Provincial propone, en una carta circular a sus religiosos, el «hacer un estudio a escala provincial que abarque la situación de la provincia en varios aspectos: [...] la adecuación a los cambios de hoy, $[\ldots]$ los procedimientos para instaurar nuevas estructuras hospitalarias». Este estudio se concretiza en un voluminoso informe que se pone en circulación en abril de 1968. Este informe abarca temas doctrinales, organizativos y económicos. Al final se hace un balance de la situación de cada centro y se evalúa su proyección futura. Este informe se discutió en la asamblea provincial (que tiene lugar cada tres años) del verano de 1968 .

Fruto de la misma fue un proyecto global de replanteamiento de la actividad asistencial de los religiosos que podríamos resumir en varios puntos clave: (a) Transformar paulatinamente los centros en régimen de clínica abierta en centros en régimen de hospital. (b) Sustituir el gobierno y la administración que en cada centro llevaba el superior local religioso por un gobierno y una administración colegial, a base de Juntas. (c) Ra- 
cionalizar la gestión económica de cada unidad hospitalaria y de toda la provincia. (d) Planificar a nivel provincial los programas de actividad y orientación asistencial de los centros. (e) Lograr que cada hospital adopte una reglamentación interna y que explicite su organigrama.

El balance de este programa se hace tres años más tarde, primavera de 1971, en vistas a una nueva asamblea provincial. En el informe aparecen plasmados, con fuerte sentido crítico, los «defectos más notables en el sistema de gobierno y organización de los hospitales» que se resumen así: (a) Gobierno unitario y autocrático, centrado en el superior religioso. Como éste cambia cada tres años, el gobierno y las directrices del hospital sufren la misma suerte. (b) Carencia de definición de objetivos, de planificación, coordinación y control de los resultados. (c) Reglamentos anticuados y sin especificación de las atribuciones de los puestos de trabajo; horarios del hospital supeditados a la comunidad; ineficacia de la jerarquización de servicios y del personal. (d) Inexistencia o deficiencia de información entre los diversos estamentos que trabajan en el hospital. (e) Las relaciones entre médicos y religiosos son escasas a nivel de estamento; son mejores a nivel individual; igualmente ocurre con el personal sanitario auxiliar, con lo que se obstaculiza a unos y a otros el identificarse con la institución y sus fines. ( $f$ ) En el aspecto económico se lamenta la estructura capitalista de la política asistencial de la provincia; se señala como inconveniente la no separación de contabilidades del hospital y de la comunidad religiosa y la ausencia de presupuestos.

Aparece asimismo en el susodicho informe otro tema ya esbozado en la asamblea de 1968 pero que aquí adquiere mayores proporciones: el de la orientación y destino futuro de los centros hospitalarios propios de la congregación. En efecto, la seguridad social española está construyendo sus centros sanitarios sin tener en cuenta los servicios benéfico-asistenciales de las congregaciones religiosas, que cubrían en parte o totalmente las necesidades locales. Frente a la potencia del coloso sanitario estatal, el hospital privado religioso (modesto suplente hasta aquí) debe buscar otra forma de invertir su potencial humano y utillaje técnico.

A guisa de comentario sobre esta problemática captada a través de estas asambleas trienales se observa lo siguiente. Primero, la importancia que adquiere la legitimación (el fundamento doctrinal e ideológico) de todo el proceso. Invariablemente cada capítulo de los informes se inicia con un acopio de razonamiento en los que las justificaciones sacadas de la Biblia, la teología, la OMS y la tradición propia del grupo religioso constituyen un verdadero tejido conjuntivo del proyecto reorganizador. Segundo, el realismo y el fuerte sentido de autocrítica que impregna los informes; los párrafos arriba citados dan buena fe de ello. Tercero, la 
importancia que se da a la gestión económica, dominio tradicionalmente descuidado por los religiosos; no faltan balances de ejercicios, cifras de coste, rentabilidad e inversiones. Por último, en el dominio de la organización interna de los centros salta a la vista que el progreso ha sido más bien escaso; romper unos moldes y hábitos seculares no será obra de tres o cuatro años.

Todo este proceso es desencadenado por un núcleo de religiosos que precisamente, a raíz de la asamblea de 1971, fueron promovidos casi todos a los puestos de responsabilidad administrativa a nivel provincial (superior provincial y secretarios consejeros). Estos cargos son por elección y ello sugiere un apoyo mayoritario de la provincia a esta política renovadora. En los años que siguen, todo parece indicar que tendrán las manos libres para coronarla o por lo menos hacerla progresar.

Así las cosas, el año 1974 se realiza el estudio sociológico mencionado al principio y que permite un análisis más fino y más de cerca de todo este proceso. Nuestra referencia, en lo que sigue, será a este trabajo.

Aunque hayamos centrado nuestro análisis en el grupo religioso, no podemos limitarnos a él ya que es sólo un elemento, entre otros varios, de la organización hospitalaria. Antes de profundizar en la dinámica del cambio situaremos dentro de aquélla cada uno de los estamentos del hospital: los médicos, los religiosos y el personal sanitario.

Siguiendo el análisis clásico de las «dos líneas de autoridad» o de las «dos lógicas», el hospital es el escenario de un forcejeo constante entre lo que la literatura especializada denomina la administración y el cuerpo médico. Aun aceptando, en líneas generales, este marco de análisis, el hospital privado religioso presenta particularidades que merece la pena matizar. Ante todo, «la administración» en nuestro caso no era - hasta ahora por lo menos- lo que podríamos llamar el vehículo de la «lógica burocrática», si por esto entendemos la racionalización de la gestión hospitalaria. Era y es, más bien, una «administración» de propietarios de un patrimonio que lo administran según una «lógica benéfico-asistencial» idealista y desinteresada. La administración es además toda la comunidad religiosa y de ahí que aparezca investida de un prestigio de naturaleza religioso-carismático en contraposición al cuerpo médico cuyo prestigio es técnico-carismático. Así pues, no se trata tanto de una confrontación entre racionalidad administrativa y el poder de un experto profesional, sino entre dos poderes carismáticos; no se trata de «servicio contra dinero», como dice Smith, sino más bien de servicio desinteresado (religiosos) contra servicio remunerado (médicos). Porque además, el conflicto, cuando aflora, no se centra tanto en los problemas económicos o presupuestarios (que también se da) cuanto en la calidad de la asistencia sanitaria la cual 
es exigida por los religiosos en nombre de su ideal altruista. Otro título para exigirla es también su destreza profesional, la cual, aun cuando no esté respaldada por diplomas elevados, sería injusto minusvalorar. Todas las consideraciones de Duhart y Charton-Brassard acerca del papel de suplencia y de responsabilidad de las enfermeras tienen aquí aplicación cabal. ${ }^{14}$ Resulta así que los religiosos, subordinados profesionalmente a los médico, tienen poder -en cuanto miembros de la comunidad propietaria, en cuanto personas prestigiadas por una dedicación total y desinteresada y en cuanto expertos a su nivel - para contestar la autoridad profesional del médico y controlar su actuación. Uno de estos últimos resumía así la situación en el decurso de una entrevista: «Hay una paradoja jerárquica: los que son nuestros empresarios son, a la vez, nuestros subordinados.»

Dentro de este escenario podríamos interpretar el sentido general del proceso de modernización como el intento de reemplazar una administración cuya autoridad se apoya en un derecbo de propiedad $y$ en un prestigio carismático-religioso por otra cuya autoridad fuera racional-legal. No es éste el lugar de descender a pormenores y mostrar cómo todo un montaje de Juntas y comités viene a estructurar un nuevo marco administrativo. Religiosos, médicos, administrativos, personal sanitario integran los diversos órganos de gobiernos que deben regir el hospital. Este proceso tiene sobre todo en cuenta a los religiosos y a los médicos. Implícitamente trata de instaurar esa advisory bureaucracy característica de los hospitales, es decir, una burocracia que da orientaciones sin constreñir, que da sugerencias a los profesionales que encuadra, aunque éstos pueden no seguirlas. ${ }^{15}$

La estrategia del cambio vis à vis del cuerpo médico consiste, por parte de los religiosos que lo patrocinan, en ceder parte de sus privilegios en favor de instancias de poder participado para así integrar al personal médico de manera más definitiva. Éste es quizás el momento más adecuado para hacerlo. Como dice A. Chauvenet, «los procedimientos de la racionalización técnica, la especialización médica, así como el recurso creciente a técnicas que registran y miden los síntomas, tienden a reducir la autonomía profesional. Al mismo tiempo, al hacer la enfermedad más legible, al convertirse el saber médico en un saber universal y no fundado solamente sobre la experiencia, esos factores preparan la instauración de con-

14. J. Duhart y J. Charton-Brassard, «Réforme hospitalière et son infirmier sur ordonnace médicale», Revue Française de Sociologie, vol 14 (1973): 77-101, p. 88.

15. Mary E. W. Goss, «Patterns of bureaucracy among hospital staff physicians», pp. 170-194, en E. Freidson (ed.), The Hospital in Modern Society (Nueva York: Free Press, 1963). 
troles administrativos». ${ }^{16}$ Frente a la tentación perpetua de los médicos de servirse del hospital como proveedor de medios técnicos, éste, si quiere promover sus propios fines, debe controlar su marcha. «¿Por qué medios es capaz de contrapesar la autonomía profesional del médico, de vincularlo al hospital? ¿Cómo frenar la tendencia de éste a la atomización en servicios más y más especializados (selectivos y particularistas), que se definen ante todo por su dependencia a un sector médico pero sin coordinación en el seno del hospital? " Éste es, precisamente, el sentido de esa maniobra que pretende, como dijimos arriba, transformar en hospital los centros que funcionan en régimen de clínica abierta, lo cual es, ni más ni menos, que romper con la práctica de la medicina liberal dentro del hospital mismo. Ahora bien, para ello es preciso ofrecer a los especialistas unos contratos remuneradores (junto con la calidad de servicios y de personal) que permita a la administración ser ella quien fije el precio de las intervenciones. Como el hospital profesa una ideología altruista y abierta a las clases desfavorecidas, podemos imaginar que el asunto no es fácil de resolver. ${ }^{18}$

A la larga, este proceso tiene repercusión directa en el título de propiedad de los hospitales que detentan los religiosos, y la actitud de los médicos ante este asunto muestra bien claramente la ambivalencia de su posición. Digamos, de entrada, que entre los religiosos hay una neta corriente que propugna desprenderse de la propiedad de los centros, corriente que se acentúa en los jóvenes. Sin embargo, entre los médicos una mayoria prefiere que los religiosos sigan siendo propietarios. Es curioso constatar que, tanto entre éstos como entre los que son contrarios a la propiedad, más de la tercera parte de los médicos entrevistados hacen alusión a que la propiedad no capacita a los religiosos para dirigir. Es evidente que la situación ideal para los médicos sería la del hospital en que ellos no tengan ninguna responsabilidad administrativa $y$, a la vez, gocen de total autonomía. Por otra parte, señalemos de pasada que interrogarse sobre la pertinencia de que los religiosos manter1gan la propiedad del hospital implica replantear totalmente el sentido de su presencia en el mismo y lleva a modificar la imagen social que tiene este tipo de centros.

16. A. Chauvenet, «Idéologies et status professionnels chez les médecins hospitaliers», Revue Française de Sociologie, vol. 14 (1975): 61-76.

17. C. Herzlich, «Type de clientèle et fonctionnement de l'institution hospitalière», Revue Française de Sociologie, vol. 14 (1973): 41-59.

18. En uno de los hospitales en que el nuevo equipo administrativo actub un poco dxásticamente al respecto, desertaron en poco tiempo unos cuantos médicos afamados con cl consiguiente detrimento para el centro. 
Por el hecho mismo de que la unidad funcional hospitalaria es una realidad bastante distinta para los religiosos y para los profesionales, la estrategia del cambio y la orientación de su proceso posee aspectos específicos para cada estamento implicado. Así como para los médicos se trataba de arbitrar nuevos modos de participación, se concentró en los religiosos una labor de mentalización y de capacitación profesional.

Una vez más remitimos el análisis de la institución total para insistir en que se trataba de romper unos moldes culturales de asistencia sanitaria, de vida en el hospital que constitufan elementos casi sacralizados de la subcultura de la comunidad. Ha habido una tarea de difusión de los problemas sanitarios actuales, una tarea de legitimación de la renovación proyectada que puede seguirse, en parte, en las revistas y escritos internos que la congregación hacía circular y que nos consta se realizaba en las conferencias y asambleas de estos últimos años. El resultado es que la casi totalidad considere en este momento que la reforma y modernización de la organización de sus centros era una tarea necesaria y oportuna.

El segundo aspecto, más fácil de controlar objetivamente, se puede resumir diciendo que hoy día muy pocos religiosos carecen de su título de ATS (Asistente Técnico Sanitario) y que, después de una primera etapa de capacitación a nivel medio, se inicia ahora una segunda (cuyos beneficiarios serán forzosamente los jóvenes) en que se parte a la conquista de los títulos universitarios en tres dominios particularmente: medicina, psicología y dirección de empresas.

\section{Balance $y$ perspectivas}

Después de toda esta panorámica, parece de todo punto indicado intentar un balance de la situación y esbozar algunas perspectivas. Tanto los religiosos, como los médicos, como el personal sanitario opinan que la reorganización que se está introduciendo en los hospitales era necesaria y oportuna. Este parecer arroja una mayoría abrumadora, más aún, si cabe, entre los religiosos. En las encuestas y entrevistas con estos últimos se recogen expresiones del estilo siguiente: «responder a las necesidades actuales», «evolucionar», «adaptarse», «estar a la vanguardia de las corrientes hospitalarias». Algunos denuncian, de paso, el retraso que había invadido la labor sanitaria de la congregación («estábamos desfasados», «anquilosados», «atrasados técnicamente»).

Los médicos, al unísono con los religiosos, apoyan calurosamente 
la reorganización de los hospitales; para unos se inscribe en la gran evolución y mutación de la sociedad actual, otros hacen hincapié en el anacronismo y desfase de las estructuras hasta ahora en vigor, para otros son los frutos de la reorganización los que cuenta, esto es, una asistencia hospitaria más eficaz en todos los sentidos. Sería instructivo analizar todo este movimiento de reorganización desde la perspectiva de la élite médica quien seguramente «actúa en el sentido de conservar sus privilegios toda vez que ha comprendido que el sistema ha de evolucionar inevitablemente y que puede obtener nuevos privilegios en contrapartida de la aceptación de los cambios». ${ }^{19}$

Ahora bien, el que haya un consenso general en que el hospital tiene que ser eficaz, rentable o moderno no prejuzga nada acerca de las actitudes concretas con que cada miembro de una unidad hospitalaria acepta un proceso de reorganización bic et nunc. En este sentido nuestra investigación abre unas pistas interesantes al sacar a luz los bloqueos y resistencias que es lógico existan.

Los religiosos (más de las tres cuartas partes de los cuales aseguran que la reorganización que se está implantando en sus hospitales era necesaria y que tienen confianza en el equipo directivo actual que las promueve) al ser interrogados dónde sitúan los «núcleos de resistencia» responden, en más de un $80 \%$, que entre ellos mismos. ${ }^{20}$ Uno de los valores de la subcultura del grupo es el de exorcizar los conflictos y, cuando existen, minimizarlos y ofrecer una faz común de unanimidad y armonía frente a los de fuera. Era de esperar, pues, que las preguntas directas que implicaban dar razón de posiciones personales se respondiesen de acuerdo con este patrón cultural. En las indirectas no actúan los reflejos de defensa. Sea como fuere, se manifiesta en el seno del grupo religioso ciertas dificultades y bloqueos en el proceso de modernización (¿podría suceder de otro modo?).

En primer lugar hemos creído captar que el grupo responsable de la reorganización ha actuado de una forma un poco drástica, movidos sin duda por la urgencia y la magnitud del trabajo a realizar. Este tipo de planificación impositiva, en cierta medida totalitaria, es el que con más probabilidad tiende a tomar cuerpo en aquellos grupos sociales en que se ha generado un proceso de «movilización», es decir, un proceso por el que los núcleos representativos de los viejos compromisos pierden vi-

19. Steudler, op. cit., p. 29.

20. El $50 \%$ lo sitúa en el seno de la provincia, y un $35 \%$ en los superiores de la Curia General de Roma. Sólo un $4 \%$ lo sitúa entre los médicos y nadie entre el personal auxiliar. 
gor y los individuos se abren a nuevas pautas de socialización y de conducta. ${ }^{21}$ Este proceso de movilización se caracteriza por una participación social más intensa $y$, en aquellas colectividades en que se instaura, emerge un grupo (un partido político, un equipo de administradores) que emprenden la tarea de planificación de la sociedad. Allí donde las metas de esta planificación son de tipo racional-industrial es fácil que ésta adopte una forma totalitaria." Por aquí apunta una de las vías de interpretación de este proceso. Indudablemente el grupo promotor-director de la reorganización juega - aunque nunca explícitamente- la carta del acatamiento religioso. También posee otras bazas para mover a los recalcitrantes pero su problema mayor radica en la no homogeneidad del grupo religioso destinatario y asiento de todo este proceso: mientras los jóvenes y aun los maduros están abiertos a él, los veteranos lo sufren. ${ }^{23}$ Es sintomático al respecto el que estos últimos confiesen en la encuesta que se encuentran dentro del nuevo hospital como arrinconados, extraños en su propia casa.

En el dominio de los estudios y la capacitación, más allá de los diplomas perseguidos, es todo un replanteamiento de la actividad del religioso lo que viene implicado. Hemos aludido a que la estructura de la vida religiosa tendía a definir a sus miembros como excelentes ejecutivos de las tareas propias del grupo. Una mayor habilidad profesional y una formación permanente (que se instaurará por la fuerza de las cosas) propenden a capacitarlos cada vez mejor para puestos administrativos y de control a todos los niveles. Un problema nuevo es que a los religiosos les resulta mucho menos remunerador, desde el punto de vista afectivo, el ocupar puestos de mando intermedios que aquellas otras faenas «a pie de cama» en que la relación con el enfermo es inmediata. Esta mutación en su tarea está plenamente inscrita en la lógica del proceso de racionalización y tecnificación del hospital en que cada vez el contacto con el enfermo está más mediatizado. Los religiosos más tradicionales, adiestrados en el derroche de energías y efectuando una gran inversión de afecto en sus enfermos, están desconcertados y su reacción es achacar a tanta

21. El término de «movilización» es de Gino Germani, y el concepto aquí de finido es de Karl Deustch.

22. Véase un esbozo de toda esta problemática en Nilda Sito et alii, Modernización y desarrollo social (Buenos Aires: Nueva Visión, 1970), pp. 15 y ss.

23. El abanico de edades que cubre esta clasificación es: menos de 34 añus $(28 \%), 34$ a 43 años $(33 \%)$ y más de 43 años $(36 \%)$. La encuesta confirma por lo demás ampliamente lo que hoy día es ya un tópico, a saber, que la generación. joven está separada de la generación antigua por un verdadero foso ideológico y le actitudes. 
técnica y tantos refinamientos el que se deshumanice la relación terapéutica. En cierto modo no están errados. ${ }^{24}$

En fin, toda la capacitación profesional de los religiosos tiene la función latente de convertirles en «interlocutores válidos» de los médicos y administrativos que trabajan con ellos. Es evidente que su proyecto institucional de infundir un espíritu a la labor asistencial en sus diversas ramas tecnológica y administrativa no pueden llevarlo a cabo si los problemas intrínsecos a esos campos les son extraños y los abordan como investidos exclusivamente de una misión religiosa.

Todo este proceso (en la medida en que se corone) abocará a una re-composición de la imagen de un religioso hospitalario. Ciertos rasgos tradicionales (hábito monástico, dedicación intensiva, ciertas formas de asistencia espiritual) son sustituidos por otros nuevos, exigidos en primacía por la cultura actual (seriedad científica, técnica depurada, atención personalizada). Es un proceso de «secularización», si por ello entendemos el que se diluyan ciertos estereotipos de la subcultura de los religiosos en el hospital. A la postre, no son los mismos signos tradicionales los que sirven de soporte al «carisma religioso». Éste conserva el desinterés, el sentido de ayuda al desfavorecido, la preocupación por la justicia; depura el sentimiento religioso; pierde el carácter de beneficencia y caridad paternalista; se enriquece con el saber y pericia técnicas.

El último tema que abordaremos es el de la coordinación en el bospital a partir de todos estos nuevos presupuestos. El hospital tradicional de religiosos ha venido funcionando a base de un acuerdo tácito entre aquéllos y el cuerpo médico, según el cual estos últimos se reservan las intervenciones clave (diagnóstico, quirófano, decisiones importantes) y dejan en manos de aquéllos, y del personal sanitario a sus órdenes, la rutina del resto del proceso curativo. Era una forma de división del trabajo demasiado aguda en que la función de suplencia habitual que el personal sanitario del hospital asume en ausencia del médico se veía aquí refrendada y reforzada por la mayor conciencia profesional de los religiosos, quienes por pundonor y por prestigio institucional llevaban una carga desproporcionada a sus competencias. El funcionamiento diario del hospital se articulaba sobre ellos. Actualmente ni la proporción de religiosos frente al resto del personal (cada vez más reducida) ni la complejidad y multiplicidad de los servicios les permiten seguir esta línea. Se trata, por tanto, de instaurar otra line que no esté informalmente articulada sobre las per-

24. Es muy significativo el porcentaje de religiosos de más de 43 años que es. timan que la capacitación profesión es causa de una "dísminución del espíritu de entrega hospitalaria». 
sonas propietarias de la institución sino que se base en la competencia personal y profesional y, por tanto, abierta a todos.

Era, con todo, de esperar ( $\mathrm{y}$ así ocurre) que los viejos hábitos de intervencionismo de los religiosos sigan aún haciéndose sentir a pesar del esfuerzo por especificar funciones a todos los niveles de la línea jerárquica. El celo profesional de los religiosos, su sentido de responsabilidad inherente a la propiedad dificultan la actuación de los nuevos mandos intermedios (de quienes son, a veces, los subordinados). La colaboración, en busca de nuevas formas menos marcadas por las diferencias de status, tropieza con esa actitud de que los religiosos consideran que «los asuntos del hospital les conciernen a ellos de preferencia y sólo en segundo término a los seglares». ${ }^{25} \mathrm{Se}$ origina así un círculo vicioso según el cual los seglares (personal sanitario) declinan parte de su responsabilidad en los dueños, y éstos se reafirman en la idea de que el hospital no puede marchar bien si ellos no están encima.

Chocamos una vez más con el problema de que las pautas propias de la subcultura religiosa están constantemente interfiriendo las pautas institucionales de una organización profesional. A la larga son éstas las que prevalecerán. Creemos que subsistirá entonces una confrontación de valores, que es lo que seguramente define la especificidad de un hospital regido por religiosos. En qué medida sistemas de valores no estrictamente concordantes (religiosos, profesionales, económicos) cristalicen en pautas comunes de actividad profesional es el problema que a largo plazo habrá que resolver.

\section{Adolfo Perinat}

Departamento de Sociología

Facultad de Ciencias Económicas

Universidad Autónoma de Barcelona

Bellaterra, Barcelona.

25. Esta opinión es suscrita por el $60 \%$ de los médicos, el $52 \%$ de los propios religiosos y el $35 \%$ del personal. 